\title{
JURISPRUDENCIA AMBIENTAL EN ARAGÓN (PRIMER SEMESTRE 2017)
}

\author{
LAURA SALAMERO TEIXIDÓ \\ Profesora ayudante doctora
}

Universitat de Lleida

\begin{abstract}
Sumario: 1. El Tribunal Superior de Justicia de Aragón suspende parcialmente la vigencia del Plan General de Pesca de Aragón para el año 2017. 2. La indemnización por la destrucción de material vegetal por fuego bacteriano o por el sacrificio de ganado tuberculoso: ¿indemnización por responsabilidad patrimonial o subvención? 3. La declaración de caducidad de una concesión de explotación de recursos mineros. 4. Sobre la constitución de un coto privado de caza y las cuestiones civiles en relación con la propiedad de las fincas que lo integran en sede contencioso-administrativa.
\end{abstract}

\section{EL TRIBUNAL SUPERIOR DE JUSTICIA DE ARAGÓN SUSPENDE PARCIALMENTE LA VIGENCIA DEL PLAN GENERAL DE PESCA DE ARAGÓN PARA EL AÑO 2017}

La Sala de lo Contencioso-Administrativo, Sección 1.ạ, del Tribunal Superior de Justicia de Aragón, auto 35/2017, de 16 de marzo, ha adoptado como medida cautelar la suspensión de la vigencia de algunos preceptos de la Orden DRS/139/2017, de 8 de febrero, por la que se aprueba el Plan General de Pesca de Aragón para el año 2017.

La medida de suspensión se enmarca en el recurso interpuesto por la Federación Aragonesa de Pesca y Casting frente a dicho Plan General de Pesca. Los recurrentes alegan la ilegalidad del Plan y, en especial, de determinados artículos que modifican el régimen de pesca de la trucha arcoíris, la carpa común y el black bass. Según el nuevo Plan, dichas especies son alóctonas, por lo que en las competiciones deportivas se prohíbe la modalidad de "captura y suelta", y, por el contrario, se impone la obligación de sacrificar dichos especímenes. La Federación alega, entre otras cuestiones, que la práctica del sacrificio no está regulada y que ello entorpecerá la mecánica de la competición, pues el deportista tendrá que sacrificar la pieza en mitad de esta. 
El Tribunal estima, después de ponderar los intereses en conflicto, que procede la adopción de la medida cautelar de suspensión. En primer lugar, se pone de manifiesto la concurrencia del periculum in mora, dado que la duración del Plan que se impugna es solo de un año y, de aplicarse las medidas de erradicación de dichas especies, se produciría un daño irreparable tanto a la dinámica de la competición como a dichas especies. Además, entiende que concurre el fumus boni iuris en atención a las modificaciones incorporadas en la Ley 42/2007, de 13 de diciembre, del Patrimonio Natural y de la Biodiversidad, por la Ley $33 / 2015$, de 21 de septiembre, por la que se modifica la Ley $42 / 2007$, las cuales permiten la existencia de excepciones a la erradicación de estas especies y la adopción de medidas de control sin sacrificio. Y añade, además, que la suspensión de la obligación del sacrificio de tales especies fluviales será en cualquier caso en beneficio y para la protección del medio ambiente.

Así, los preceptos cuya vigencia se suspende son los siguientes:

- La inclusión en el artículo 2.2 de la trucha arcoíris, la carpa común y el black bass, que pasan a regularse conforme al artículo 2.1 como especies pescables en la modalidad de captura y suelta (sin muerte).

- Los artículos 2.5, 4.3, 14.1, 14.2, apartados a), c), d) y e), 14.3, 15, 28.4 b), 33.1, 36.1, 36.2 y el anexo XII, en la medida en la que impiden el sistema de captura y suelta $y$ obligan al pescador a sacrificar inmediatamente y de forma rápida los ejemplares capturados de trucha arcoíris, carpa común y black bass.

\section{LA INDEMNIZACIÓN POR LA DESTRUCCIÓN DE MATERIAL VEGETAL POR FUEGO BACTERIANO O POR EL SACRIFICIO DE GANADO TUBERCULOSO: ¿INDEMNIZACIÓN POR RESPONSABILIDAD PATRIMONIAL O SUBVENCIÓN?}

Durante el semestre que estudiamos, el Tribunal Superior de Justicia de Aragón ha dictado dos sentencias relativas al ya clásico tema de las indemnizaciones asociadas al sacrificio de ganado o a la destrucción de material vegetal por motivos de sanidad vegetal o animal. La cuestión radica en dilucidar si nos hallamos ante un supuesto de responsabilidad patrimonial 0 , 
por el contrario, se trata de actividad de fomento de la Administración cuando se prevé la indemnización ante la concurrencia de tales daños.

La Sentencia del Tribunal Superior de Justicia de Aragón 7/2017, de 13 de enero (Sala de lo Contencioso-Administrativo, Sección 3.a ), recurso núm. 109/2014, trae causa de la destrucción de material vegetal contaminado por fuego bacteriano en unos viveros.

De conformidad con el artículo 21 de la Ley 43/2002, de 20 de noviembre, de Sanidad Vegetal, "[c]uando las medidas establecidas para la lucha contra una plaga supongan la destrucción, deterioro 0 inutilización de bienes 0 propiedades particulares o públicas, la Administración competente que haya declarado la plaga compensará a los perjudicados mediante la debida indemnización, cuyo importe se valorará de acuerdo con los baremos que se establezcan. No se concederá indemnización cuando tales medidas se hayan hecho necesarias como consecuencia de transgresiones a la presente Ley o a las disposiciones promulgadas en desarrollo de la misma".

De acuerdo con tal previsión, la parte demandante fue indemnizada por un importe de aproximadamente $60.000 €$. Ahora bien, no conformes con dicho importe, los titulares de los viveros recurren la resolución administrativa y reclaman un importe mayor que cubra todos los perjuicios ocasionados por la destrucción del material vegetal contaminado por el fuego bacteriano.

Para resolver el recurso, tal como razona el TSJ, es necesario en primer lugar dilucidar la naturaleza jurídica de la indemnización que recoge el artículo 21 de la Ley de Sanidad Vegetal, cuestión no del todo pacífica entre la doctrina. Si se concibe como una indemnización por responsabilidad patrimonial, al afectado le es reconocido el "derecho a ser indemnizado por toda lesión que sufra en cualquiera de sus bienes y derechos, salvo en los casos de fuerza mayor, siempre que la lesión sea consecuencia del funcionamiento de los servicios públicos" (art. 106.2 de la CE). El Tribunal, no obstante, estima que no puede entenderse que nos hallemos ante un supuesto de responsabilidad patrimonial, ya que el daño sufrido no es antijurídico, uno de los requisitos para que concurra este instituto. El Tribunal considera que tampoco se trata de un supuesto de expropiación forzosa que deba indemnizarse con un justiprecio, 
aunque no justifique por qué. Según el órgano judicial aragonés, nos hallamos ante actividad de fomento de la Administración, puesto que mediante el estímulo económico se pretende el cumplimiento de un objetivo determinado, en este caso, la eliminación del foco bacteriano para evitar su propagación y la causación de mayores daños.

En fin, la postura que mantiene el Tribunal aragonés coincide con la jurisprudencia mayoritaria y constante, que rechaza que este tipo de actividad pueda recibir la consideración como supuesto de responsabilidad patrimonial, conceptuándose como acción de fomento.

Sentado lo anterior, el Tribunal valora si el importe fijado por la Administración aragonesa se ajusta a la legalidad o no. El Tribunal entiende que la Administración está ejerciendo en este marco una potestad discrecional, de modo que su valoración atiende a la motivación, que se considera suficiente. En consecuencia, se desestima el recurso.

Por su parte, la Sentencia del Tribunal Superior de Justicia de Aragón 14/2017, de 30 de enero (Sala de lo Contencioso-Administrativo, Sección 3.a), trae causa del sacrificio de ganado vacuno a consecuencia de la detección de tuberculosis en las reses. Los ganaderos afectados reclaman a la Administración que responda en concepto de responsabilidad patrimonial basándose en la alegación de que la actuación de la Consejería de Agricultura, Ganadería y Medio Ambiente para erradicar la tuberculosis bovina en las reses fue deficiente.

El Tribunal aragonés de nuevo se remite a la jurisprudencia mayoritaria, con cita de algunas sentencias del Tribunal Supremo en las que se recuerda que, para que concurra el instituto de la responsabilidad patrimonial, es necesaria la existencia, entre otros requisitos, de un daño antijurídico. Recuerda también que, cuando en el marco de la acción de responsabilidad patrimonial, el demandante alega falta de diligencia en la función de vigilancia y control sanitario, le corresponde a esta parte "la carga de la prueba de los hechos imputados y relevantes para la sostenibilidad de la pretensión, es decir, que la administración competente no fue diligente en la adopción de medidas para erradicar la tuberculosis bovina en las explotaciones ganaderas referenciadas, 
y que de esa falta de actividad derivan los resultados dañosos que se imitan" (FJ 4. $\left.{ }^{\circ}\right)$.

Así las cosas y en atención a las pruebas periciales practicadas, el Tribunal sostiene que la demandante no consigue demostrar la falta de diligencia de la Administración. Se dice que "no se ha acreditado que la administración haya incumplido sus obligaciones de control ni ha quedado probada la relación de causalidad entre la enfermedad aparecida en la explotación de los demandantes y la actuación —omisión-que se achaca a la Administración, quien no es responsable del daño sufrido sino que debe ser soportado como riesgo propio de la actividad ganadera". En consecuencia, el daño resultante no puede recibir la consideración de antijurídico, sino que se trata de un riesgo propio de la actividad económica llevada a cabo por los demandantes. Por todo ello, el recurso es desestimado.

No obstante, en esta última sentencia no se indica, ni en el relato de los hechos ni a lo largo de la fundamentación, que la parte demandante haya sido indemnizada en concepto de subvención, de conformidad con el artículo 21 de la Ley 8/2003, de 24 de abril, de Sanidad Animal. En este sentido, recuérdese que, igual que la Ley de Sanidad Vegetal, la Ley de Sanidad Animal establece la indemnización en los siguientes términos: "El sacrificio obligatorio de los animales y, en su caso, la destrucción de los medios de producción que se consideren contaminados dará lugar a la correspondiente indemnización por la autoridad competente, en función de los baremos aprobados oficialmente y en la forma y condiciones establecidos reglamentariamente".

\section{LA DECLARACIÓN DE CADUCIDAD DE UNA CONCESIÓN DE EXPLOTACIÓN DE RECURSOS MINEROS}

En la Sentencia del Tribunal Superior de Justicia de Aragón 500/2016, de 23 de noviembre (Sala de lo Contencioso-Administrativo, Sección 2. a), se resuelve el recurso interpuesto frente a la declaración de caducidad de la concesión para la explotación de recursos mineros de la clase $\mathrm{C}$. Tras un exhaustivo relato de los hechos, se concretan los fundamentos del recurso de la demandante. 
Por una parte, la demandante alega la concurrencia de vicios procedimentales en el desarrollo del procedimiento de caducidad, tales como que fue un solo órgano el que tramitó el procedimiento, sin que se distinguiera entre el órgano instructor y el órgano encargado de resolver. Frente a tal alegación, el TSJ aragonés acertadamente estima que "[...] la caducidad de los permisos y concesiones mineras no tiene naturaleza sancionadora. En efecto, la declaración de caducidad de un derecho de investigación de minas de ninguna manera puede ser configurado como una sanción, sino como la pérdida de un derecho que deriva del incumplimiento por la parte interesada de las condiciones jurídicas impuestas en virtud de una relación jurídica especial, en este caso de la autorización concedida por la Administración pública en relación con el demanio público minero". Así pues, no existe exigencia legal alguna que imponga que el órgano encargado de resolver el procedimiento sea distinto del instructor.

Por otra, la parte demandante también alega que el procedimiento no fue incoado por el órgano competente para ello y que se tramitó sin el informe del Departamento de Medio Ambiente. Tales alegaciones son igualmente desestimadas por el Tribunal, puesto que el órgano que incoó el procedimiento era competente y la ausencia del informe del que hablan los recurrentes no impedía la tramitación del procedimiento.

Más allá de estas y alguna otra cuestión formal alegada por la demandante, interesa atender a las alegaciones relativas al fondo de la cuestión: los motivos que justifican la caducidad de la concesión. Dicha declaración de caducidad se fundamenta en los apartados e), g) y j) del artículo 109 del Real Decreto 2857/1978, de 25 de agosto, por el que se aprueba el Reglamento General para el régimen de la minería:

e) Por incumplimiento grave o, en su caso, reiterado de los plazos, forma e intensidad de los trabajos aprobados en los proyectos y planes de labores. $[\ldots]$

g) Cuando habiéndose paralizado los trabajos sin autorización previa de la Delegación Provincial o de la Dirección General de Minas e Industrias da la Construcción, según proceda, no se reanuden dentro del plazo de seis meses a contar del oportuno requerimiento. En los casos de reincidencia 
en la paralización no autorizada de los trabajos, la caducidad podrá declararse sin necesidad de requerimiento previo. [...]

i) Por expirar los plazos por los que fueron otorgadas las concesiones 0 , en su caso, las prórrogas concedidas.

La parte recurrente estima que la aplicación de la norma no se ha ajustado a los hechos y que no correspondía la declaración de caducidad de la concesión minera, sino, a lo sumo, un requerimiento para que se retomaran los trabajos. El Tribunal, que desestima también esta alegación, pone de manifiesto que la parte pretende reinterpretar los hechos que constan en diversas actas levantadas por los servicios de inspección correspondientes, y concluye que "[s]e ha probado y argumentado, en fin, la inactividad de la empresa", lo cual supone, en definitiva, un "incumplimiento grave o, en su caso, reiterado de los plazos, forma e intensidad de los trabajos aprobados en los proyectos y planes de labores" (art. 109.c)). Por todo ello, se desestima el recurso.

\section{SOBRE LA CONSTITUCIÓN DE UN COTO PRIVADO DE CAZA Y LAS CUESTIONES CIVILES EN RELACIÓN CON LA PROPIEDAD DE LAS FINCAS QUE LO INTEGRAN EN SEDE CONTENCIOSO- ADMINISTRATIVA}

En la Sentencia 12/2017, de 25 de enero, el Tribunal Superior de Justicia de Aragón (Sala de lo Contencioso-Administrativo, Sección 1.ạ) se ocupa del recurso frente a la constitución de un coto privado de caza, confirmada en primera instancia.

La disputa, sin entrar en detalles, radica en la extensión de dicho coto, puesto que la recurrente pone en cuestión que los titulares del coto dispongan de un título legítimo de uso y ocupación de ciertas fincas que lo integran. Se llega a afirmar que el coto integra 600 ha que no pertenecen a los titulares. En este sentido, se critica que la resolución del Instituto Aragonés de Gestión Ambiental por la que se acuerda la constitución del coto de caza y su confirmación por el juzgado de instancia toman en consideración los datos del catastro, registro cuya información no es prueba de titularidad. 
El Tribunal Superior de Justicia de Aragón estima el recurso interpuesto, pues entiende que, a pesar de tratarse en el fondo de una cuestión de orden civil, le compete a la Administración y, en sede de recurso, al órgano judicial correspondiente dilucidar la cuestión de la titularidad para poder resolver de forma ajustada a derecho sobre la constitución del coto privado de caza. Ello es así porque la titularidad del terreno o de otros derechos reales o personales que conlleven el uso y disfrute del aprovechamiento de la caza es requisito sine qua non para la constitución de un coto privado de caza (artículo 16 de la Ley 1/1970, de 4 de abril, de Caza).

Así las cosas, el Tribunal empieza por recordar que, aunque se trate de cuestiones de orden civil:

[...] el artículo 4 de la Ley 29/1998 establece que "1. La competencia del orden jurisdiccional contencioso-administrativo se extiende al conocimiento y decisión de las cuestiones prejudiciales e incidentales no pertenecientes al orden administrativo, directamente relacionadas con un recurso contencioso-administrativo, salvo las de carácter constitucional y penal y lo dispuesto en los Tratados internacionales" y que "2. La decisión que se pronuncie no producirá efectos fuera del proceso en que se dicte y no vinculará al orden jurisdiccional correspondiente".

Asimismo, el TSJ recuerda que el catastro no es un registro de la propiedad, de modo que no puede constituirse como instrumento de prueba válido en este sentido. Así, estima que deben tenerse en cuenta en el pleito los instrumentos de prueba que aporta la recurrente y mediante los cuales se acreditan, a juicio del TSJ, sus alegaciones en relación con la titularidad de las fincas del coto. 